\title{
Maintenance and testing protocols in the railway industry
}

\author{
Alessandro Massaro ${ }^{1}$, Emanuele Cannella ${ }^{1}$, Giovanni Dipierro ${ }^{1}$, Angelo Galiano ${ }^{1}$, Giovanni D’Andrea ${ }^{2}$, \\ Giorgio Malito²
}

${ }^{1}$ Dyrecta Lab IT Research Institute, Via Vescovo Simplicio, Conversano (BA), 70014, Italy

${ }^{2}$ Medtec s.r.l., Fraz. Traversa n. 4, via J. F. Kennedy n.28, Rende (CS), Italy

\section{ABSTRACT}

This paper introduces new maintenance and testing protocols regarding processes in the railway industry. The first protocol is general and can be applied to industries working in similar production processes. The second and third protocols are more specific to the railway industry and concern the turning-machine production line and the pneumatic testing of train braking systems, respectively. This study has been conducted within the framework of industry research on the design of intelligent control and actuation systems suitable for auto-adaptive Industry 5.0 facilities.

\section{Section: RESEARCH PAPER}

Keywords: Railway; protocol; maintenance; test; QR code

Citation: Alessandro Massaro, Emanuele Cannella, Giovanni Dipierro, Angelo Galiano, Giovanni D’Andrea, Giorgio Malito, Maintenance and Testing Protocols in Railway Industry, Acta IMEKO, vol. 9, no. 4, article 2, December 2020, identifier: IMEKO-ACTA-09 (2020)-04-02

Section Editor: Leopoldo Angrisani, University of Naples Federico II, Italy

Received September 23, 2019; In final form August 4, 2020; Published December 2020

Copyright: This is an open-access article distributed under the terms of the Creative Commons Attribution 3.0 License, which permits unrestricted use, distribution, and reproduction in any medium, provided the original author and source are credited.

Corresponding author: Alessandro Massaro, e-mail: alessandro.massaro@dyrecta.com

\section{INTRODUCTION}

According to the Frascati Manual guidelines [1], knowledge gain $(\mathrm{KG})$ represents an important challenge in the field of industrial research and development $(\mathrm{R} \& \mathrm{D})$. Following Industry 4.0 logic, KG can be improved through enabling technologies, such as the Internet of Things (IoT) [2] and using digitised traceability [3] for the automation of processes [4]. Specifically, in manufacturing control systems, traceability plays a crucial role in the monitoring of the state of specific components in a system [5]. As traceability technologies can be applied to industrial processes, barcode and/or QR code [6]-[12] technologies are useful for supply chain management [11], [12]. The traceability of processes is, therefore, an important part of the risk management process [13] and can also be applied to testing procedures [14]-[16], leading to a general improvement of working and testing protocols by means of IoT-supporting technology upgrades and multiple data systems [17]-[18]. Another important issue for the optimisation of manufacturing production is process mapping, which can be implemented by 4M (manpower, material, methodology, machine) charts [19][20], the PDCA (Plan-Do-Check-Act) cycle [21]-[22] (according to ISO 9001:2015), Xm-R charts [23]-[24] and p-control charts [25]-[27]. According to recent literature, there are alternative approaches that facilitate process mapping, namely the enhanced
DMAIC (define, measure, analyse, improve, control) or eDMAIC model [28], machine learning oriented towards production quality [29] and artificial neural networks that enable predictive maintenance in Industry 4.0 [30]. Controlling sensors within production processes could be adopted to check robotic arm control and actuation if they are interconnected through an intelligent unit [31].

In this paper, we propose a traceable approach to manufacturing control systems in which the maintenance process is organised in a structured and systematic way. Traceable and systematic processes make it possible to identify each phase and eventually take corrective action. This is particularly difficult if there is no structure or schedule for these activities, even if it may not appear relevant at first sight. Focusing on an industry working with train-part processing [32] and testing as a case study, we apply the proposed protocols to the turning processes and pneumatic testing of train braking systems using digitised traceability (see scheme in Figure 1). The proposed protocols are based on the concepts described in the state-of-the-art, which includes the new auto-adaptive intelligent control facilities and an actuation process improved by artificial intelligence (AI), as set out in Figure 2. In particular, we will discuss a generic protocol usable for all manufacturing industries and another two specific protocols that relate to the case study presented, which concern the process and test mapping of turning-machine operations and braking tests, respectively. 


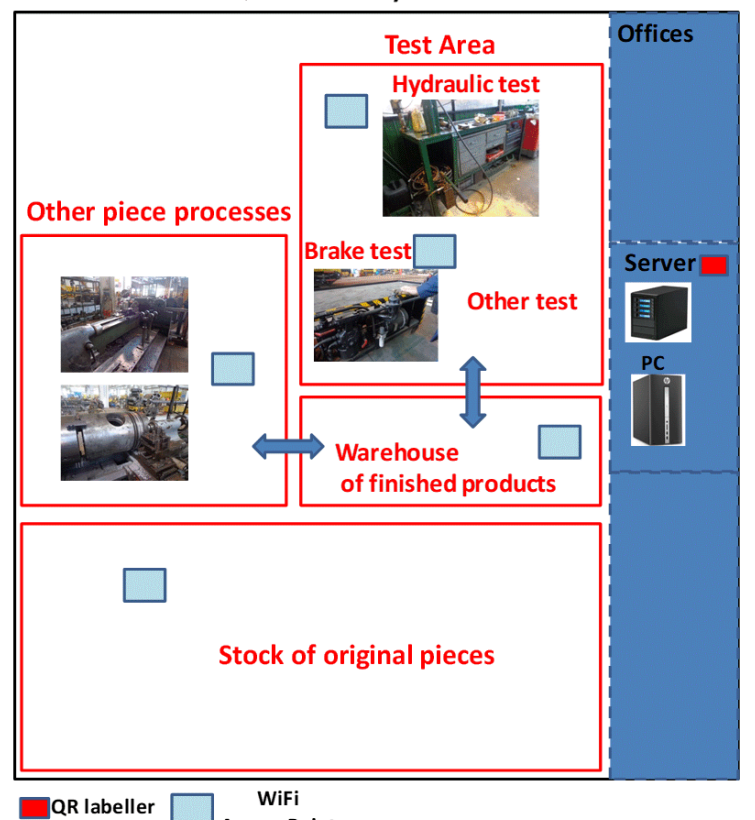

(b)

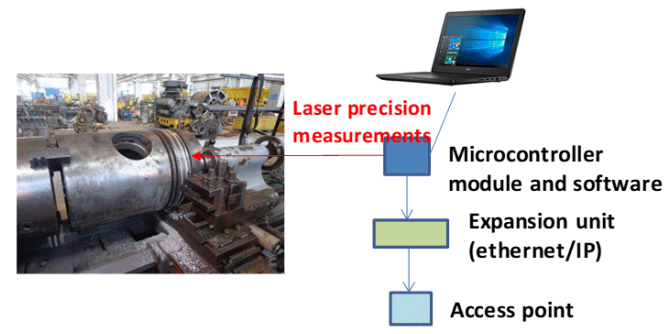

(c)

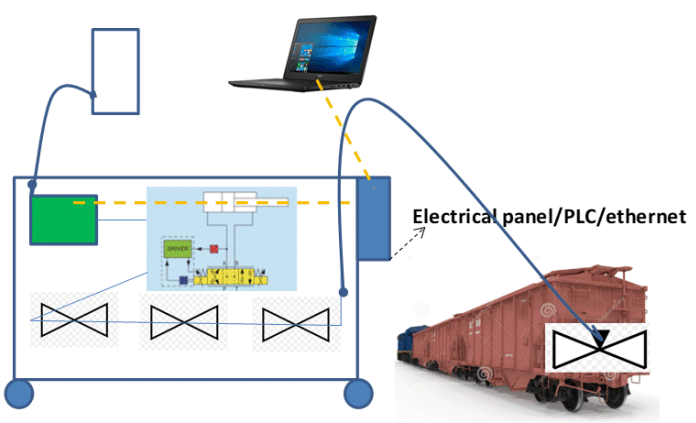

Figure 1. Study case [32]: (a) functional scheme of the layout designed for industrial traceability; (b) optical sensor system that estimates accuracy in turning processes; (c) schematic layout of the bench designed for the pneumatic testing of train braking systems.

\section{FIRST PROTOCOL: GENERIC PROCEDURE FOR PART PROCESSING}

When the maintenance of a locomotive or a generic wagon is required, faulty components are generally disassembled, investigated and restored through the manufacturing process, mostly based on cutting-edge technologies. Several procedures can be carried out for this purpose, such as turning, cutting, milling, reaming and polishing, depending on the type of renovation required. Usually, a faulty component is either broken or damaged in terms of its functional characteristics. For

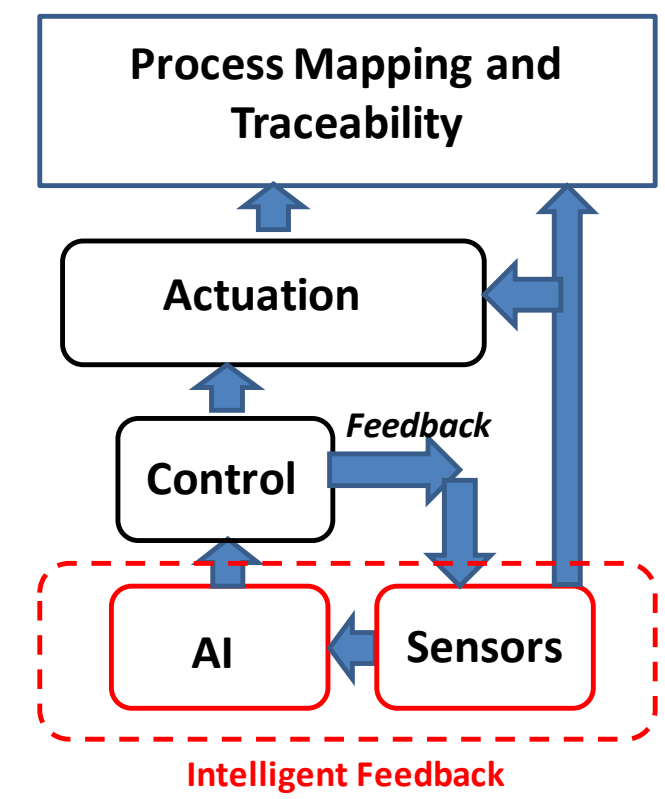

Figure 2. Intelligent control and actuation process for the generic working protocol in manufacturing processes.

example, a gear wheel can be worn, and the shape of the teeth may deviate from the original design, generating an inefficiency within the system where it is employed. The restoration of such a component could therefore be carried out on the profiling of the gear shape, e.g. by using a turning machine. The evaluation of the problem and the process for solving it are usually achieved through 'operator experience', producing a maintenance process that is strictly dependent on the operator and, thus, not repeatable. Each operator in a specific workshop has different skills and degrees of experience in the field, leading to components that are restored and tested in several different ways. Moreover, restoring the components to their original and defect-free condition is challenging. The different wear mechanisms of industrial components (adhesive, fatigue, etc.) and different stress and strain concentration mechanisms (asperity, dent, etc.) can irreversibly affect the overall amount of wear.

Therefore, the maintenance process restores components to their original functionality, but it may marginally affect the amount of wear of these components. The restoration process will therefore increase the amount of wear. After maintenance, the wear evolution and the maximum operating time of the component will be affected, which may change the effectiveness of the components over time.

A possible solution to this, proposed by the present authors, is based on developing a traceable approach, where every single phase of the maintenance process is organised in a structured and systematic way, i.e. process mapping and test mapping. This can be clearly represented by a theoretical protocol, as shown in the flow chart in Figure 3. In this case, the protocol is meant to be generally applied, independent of the type of component and operation.

The main protocol is applied to the workpiece that requires maintenance. It becomes clear that the workpiece is not working correctly, and some critical issues are therefore investigated. First, a QR code reference would be fundamental in gaining insights into the history of the workpiece, namely, the life cycle of the component, the total number of maintenance operations it has undergone and the type of maintenance. The overall 
If out-of-tolerance, go back to the problem definition

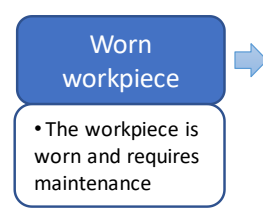

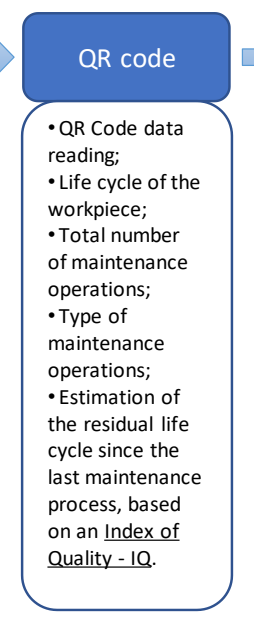
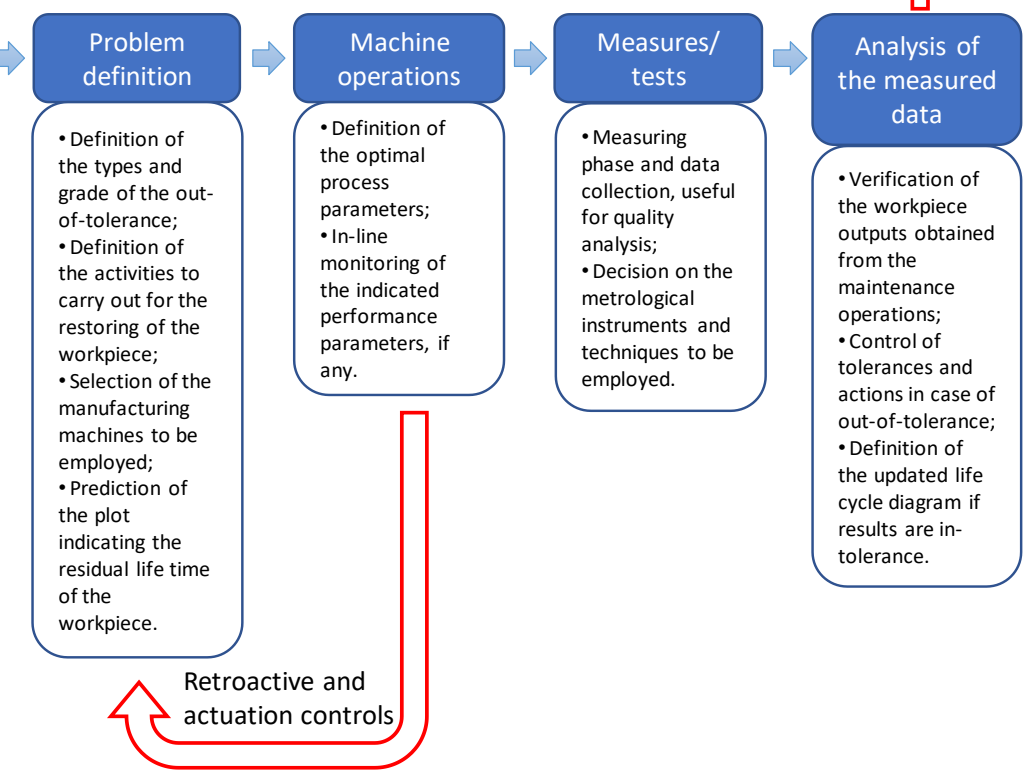

Updating the QR code

- Update of the total number and types of maintenance operations; - Update of the new life cycle diagram obtained for the estimation of the residual life.

Figure 3. Macro protocol designed for general maintenance operations in the railway industry.

amount of wear of the component can be inferred based on an estimate of the operating working cycles and a model of the evolution of the amount of wear related to that specific component.

The QR code has to be unique to that specific component. Additionally, for predictive maintenance purposes, the QR code also indicates the life-prediction curve of the tool, plotted in terms of an Index of Quality (IQ) as a function of the number of working cycles. An example of such a diagram is plotted in Figure 4. It can be theoretically described by an exponential law that fits Equation 1:

$$
I Q(x)=\mathrm{e}^{-\lambda x},
$$

where $\lambda$ is a coefficient that determines the slope of the curve and $x$ is the number of working cycles.

The IQ values are expected to vary from 0 to 1 , indicating an end-life and a new component, respectively. Generally, the IQ value and its evolution within the working cycles are closely

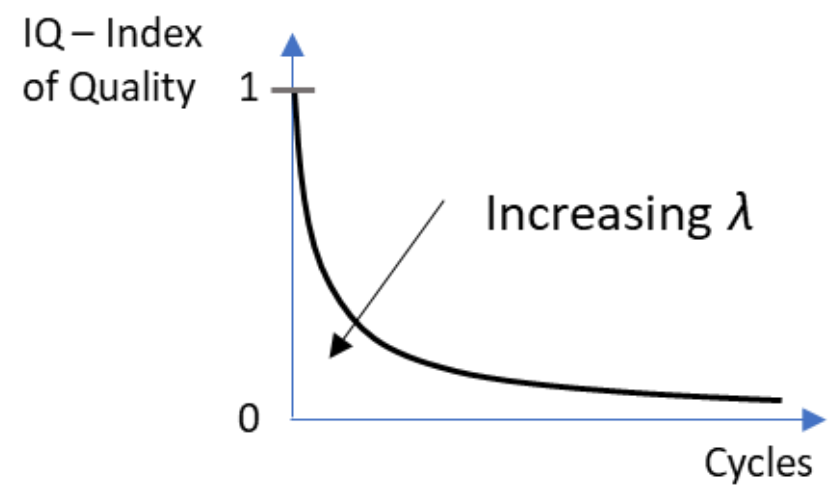

Figure 4. Theoretical exponential model describing the residual lifetime of a workpiece as a function of a specific Index of Quality (IQ). related to the overall amount of wear of the component. The scope of the maintenance is to restore the value of the IQ as close as possible to the unit value. However, since the amount of wear cannot be restored to its original state, the time evolution of the IQ value is expected to be significantly affected after the maintenance process. More specifically, this might lead to an increase in the slope of the curve (i.e. an increase in the value of $t$ in Equation (1), indicating a more rapid degradation of the component while working. This is shown in the theoretical diagram in Figure 5.

In summary, the $\mathrm{QR}$ code provides all the required historical data that could play a key role in defining the problem. Indeed, the problem is, therefore, analysed and the activities scheduled in order to proceed with the maintenance process. In this phase, all the features and parameters of the workpiece, which are found to be out-of-tolerance, have to be corrected by applying manufacturing procedures, which, in the case of a metallic material, consist of several machines that mainly perform milling and turning. Each process has its own characteristics, in terms of

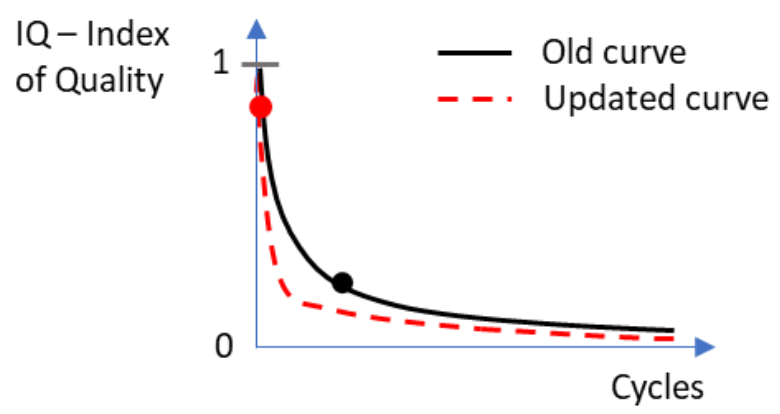

Figure 5. Theoretical exponential model describing the tool life curves predicted after maintenance in the case of a generic component. The IQ is enhanced, as shown by the red-dotted curve and compared to the black one, but the workpiece is more sensitive and degrades faster. 
Problem

Process Mapping

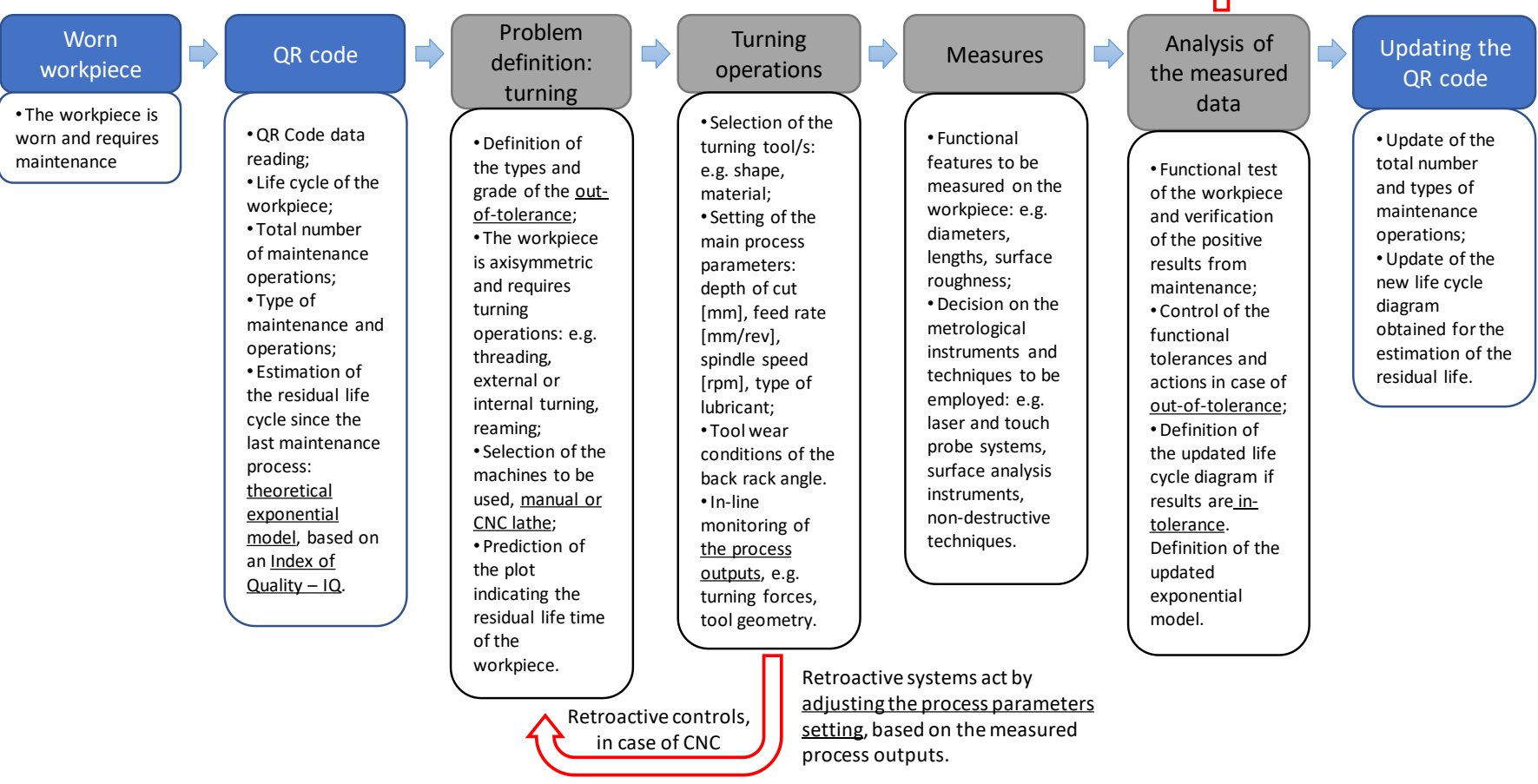

Figure 6. Maintenance protocol adapted to turning operations.

parameters, that need to be correctly set and optimised. This will be analysed in depth in relation to turning in Section 3. At the first attempt, based on the set parameters and the wear grade of the workpiece, a draft tool life curve after maintenance could be predicted.

When machines and procedures are set, the process mapping suggests that the maintenance procedure be initiated. The process parameters are optimised by referring to the historical data and based on the requirements of the maintenance process. If possible, in this phase, specific outputs should be assumed to be the 'fingerprints' of the process. This approach has also been followed by other research concerning similar manufacturing engineering fields [32], [33]. These outputs may provide information on how best to conduct the restoration process, and, if the values measured are out-of-range, they can trigger proper actuation controls that enable the correction of the previously set process parameters, as suggested in Figure 3.

After the workpiece has been restored and fixed, proper tests should be selected and carried out to check the quality of the restoration. Of course, these tests are made for the key functional features that are required to be improved/fixed. Data is thus collected in order to be analysed.

The data analysis is made by checking that the values of the key functional features are within the designed working intervals. If this is not the case, the flow chart indicates the necessity of reconsidering the problem definition and, therefore, proceeding with a second round as soon as all the functional values are measured within the tolerance range. This step is important for a systematic evaluation of a successful maintenance process, which gives an objective evaluation of the result without relying only on the operator's experience. Of course, it is fundamental that all the functional features are correctly identified in the phase definition.

At the end of the process, the protocol suggests that the QR code be updated with the new data. A new life-cycle diagram is then built by following the description previously given. This data will be the starting point for the next phase of maintenance of a specific workpiece, given that each component is uniquely defined by a QR code.

In Sections 3 and 4, two specific cases in which this approach has been applied are described and the interconnection between the different protocols is also highlighted.

\section{SECOND PROTOCOL: TURNING MACHINE CONTROL AND ACTUATION}

By following the general approach described in Section 2, a study case is now discussed concerning its application to turning processes for renovating axisymmetric workpieces. The flow chart shown in Figure 6 is made by adapting the theoretical approach of the diagram seen in Figure 5. The first steps are the same and, therefore, start with the workpiece definition, identification of the key functional features and analysis of the historical data given by the unique QR code. To highlight the chart's interconnections, the same colour (blue) shows those process steps that are mainly the same. Conversely, the grey colour characterises those elements identified as specific to a turning operation.

Turning is a well-known machining process that is based on the usage of a horizontal lathe. Usually, the processed workpiece 


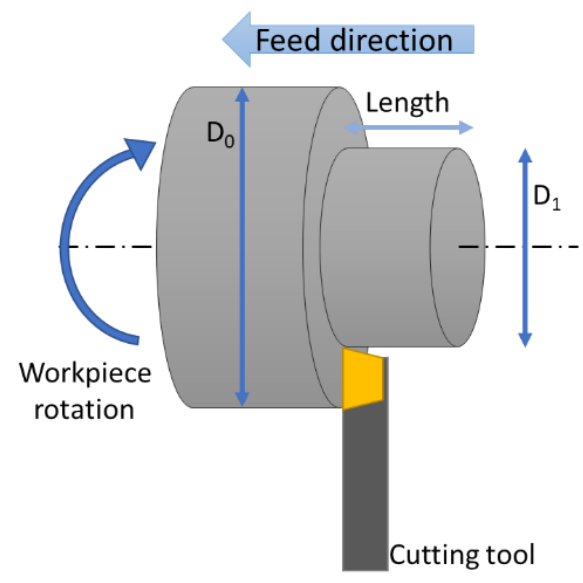

Figure 7. Schematic drawing showing the functional principle of a turning operation.

has axisymmetric features. Several operations can be done by turning depending on the tools used and the process approach, e.g. drilling, cutting, threading and polishing. The main characteristic of turning processes is that the workpiece is clamped at the machine spindle, which rotates at a set rotational speed. The cutting tool is thus making contact with the rotating workpiece (see Figure 7), interacting with the workpiece and generating the so-called chip removal.

A turning operation is correctly managed by setting four main process parameters:

- Depth of cut (mm)

- $\quad$ Spindle speed (rpm)

- $\quad$ Feed rate $(\mathrm{mm} / \mathrm{rev})$

- Presence of lubricant/refrigerant.
These parameters are extremely important for the optimisation of the output characteristics. By identifying the most critical outputs, i.e. geometrical and dimensional tolerances and surface roughness, those parameters can be related in order to apply an in-line process control. The optimisation of turning operations has been studied by several researchers [34]-[36]. The retroactive controls designed within the process mapping have the role of being actuated for the in-line correction of the process parameter values. As outputs to be used for the monitoring of the turning process, force and wear measurements are the most consistent. The force is measured by using a piezoelectric load cell mounted on the cutting tool. The tool wear is monitored by using vision systems, e.g. image vision technologies, laser systems or optical coordinate-measuring machines (CMMs). The surface roughness of the workpiece is another key feature; however, the in-line monitoring of such parameters may be difficult to undertake. Of course, other features may be involved in this analysis, but this would be strictly dependent on the functional properties of the tool being renovated. The support given by the actuation systems helps in terms of cycle time and maintenance efficiency. These elements represent the main limitation of the manual maintenance carried out only through operator experience.

Quality control can clearly only be done after the turning process to test the quality of the restoration process. As already described in the generic flow chart in Figure 2, the key features are investigated to check the success of the maintenance operation, and the correct instrumentation has to be selected and employed. Data is therefore analysed and actions have to be taken if there is an indication that any features are out-oftolerance, meaning that the process requires additional steps to ensure the component attains the desired geometry and functionality.

\begin{tabular}{|c|}
\hline $\begin{array}{c}\text { Testing } \\
\text { railway } \\
\text { locomotive }\end{array}$ \\
\hline $\begin{array}{l}\text { - The railway } \\
\text { loco motive has to } \\
\text { be tested }\end{array}$ \\
\hline
\end{tabular}

QR code
- QR Code data
reading;
- Time history of
the locomotive;
- Estimation of
the total number
of braking and
release cycles of
the locomotive;
- Number of test
done and
average time
between tests;
- Important
restoring
operations on
the brake
system.

If critical component/s is/are fixed, proceed with the testing

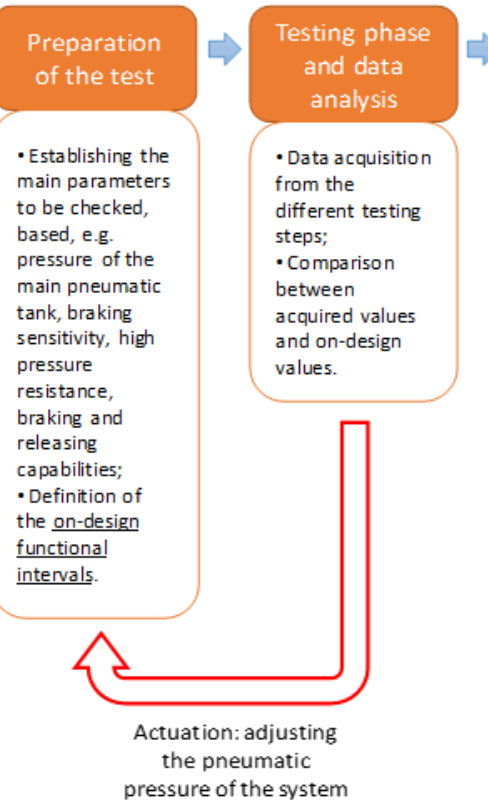

pressure of th
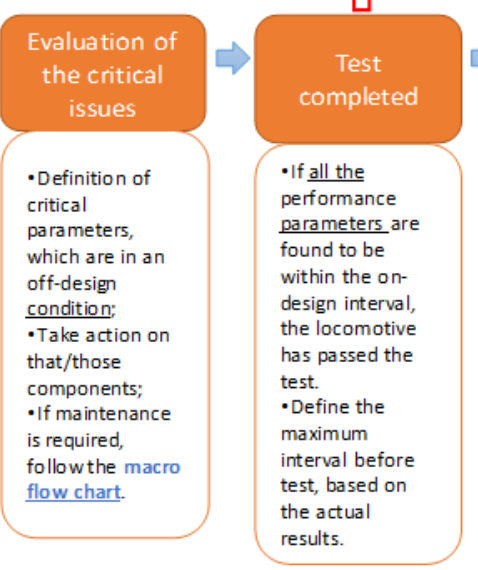

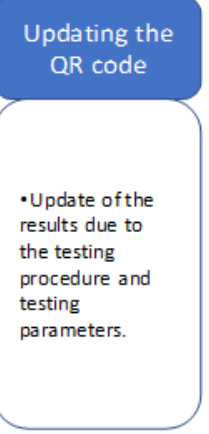

Figure 8. Maintenance protocol adapted to turning operations. 
As a last step, each operation is recorded within the unique QR code with a definition of each of the main steps carried out and the generation of a new life-cycle curve, as shown in Figure 5.

\section{THIRD PROTOCOL: BRAKING SYSTEM AND PNEUMATIC TEST OF TRAINS}

The two previous protocols, discussed and shown in Figure 3 and Figure 8, describe process mapping charts concerning the maintenance process steps for a railway workpiece. The following section proposes that the same scheme, as discussed in the introduction of this article and shown in Figure 2, be adapted for a particular testing process carried out when checking the efficiency of locomotive brakes. The scheme is therefore referred to as the test mapping chart (see Figure 8). The quality control of locomotive brakes is an important test for safety and efficiency reasons. As with the previous maintenance mapping charts, every process starts with an analysis of the $\mathrm{QR}$ code, which is unique and should include all the important information concerning the locomotive's historical data, with particular reference to the brake tests.

A typical braking system for locomotives consists of a pneumatic circuit enabling the mechanical pads to act on the rotating wheel. This system starts from the locomotive, and a circuit propagates the pneumatic force when the brakes are activated, as shown in Figure 9. Railway brakes have three principal roles:

- Reducing or stopping the speed of the train

- Balancing its weight while on slopes to maintain a constant speed

- Parking the train when stationary or at a station stop.

The testing of the brake system can be done through an automated test setup. The pressure values in the brake pipe, braking cylinder and auxiliary reservoir are checked primarily to assess their effectiveness. These parameters are plotted as a function of time and compared to the design curves, which are determined under optimal conditions.

The test system works using a pressure stabilisation approach. Proper connectors make it possible to associate the locomotive being tested with the brake-check apparatus. When the locomotive is connected, the pressure of the test system is adjusted by increasing the pressure value in the brake system

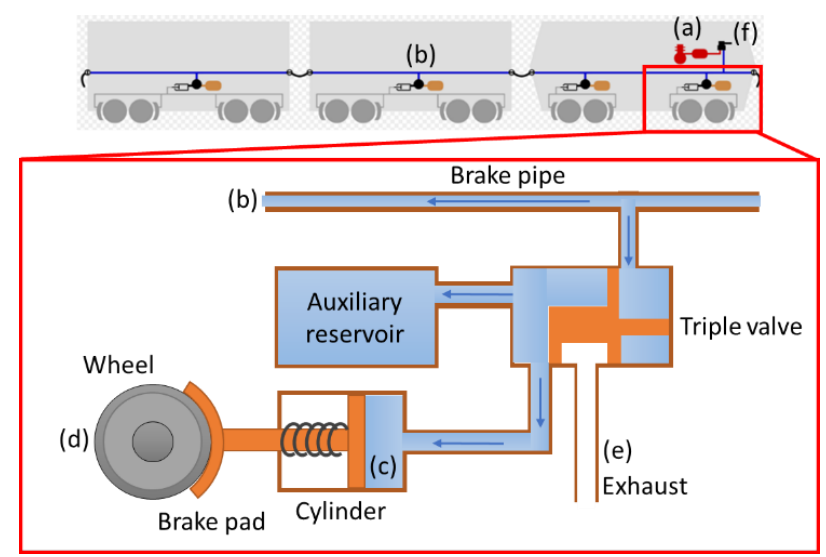

Figure 9. Schematic drawing showing the pneumatic system of a train brake and the pneumatic action while braking: (a) main air tank, (b) generic pipe, (c) brake cylinder, (d) brake wheel, (e) exhaust pressure system and (f) central braking controls and emergency button. being tested. This makes it possible to check the functionality of the brake by measuring the time required to reach a certain pneumatic pressure and then release it. This method is consistent with the starting preamble shown in Figure 2. After the test has been conducted, the system generates a report. As a sample, a case study of a test of an ordinary locomotive is shown in Table 1. It is important to check these results to establish whether the obtained values lie within the functional intervals. If the data shows that the values are off design, action on the locomotive must be taken. The test protocol thus suggests the identification of the critical elements and, therefore, the need to proceed with the macro protocol shown for the maintenance of the railway elements (see Figure 3). After maintenance, the locomotive should be checked again to test the proper functional and safety conditions of the entire braking system.

Conversely, if the results show that the values lie within the design intervals, the test should be considered as successfully completed. No action is therefore required for maintenance. This report is subsequently saved in the QR code for traceability reasons. In addition, the data obtained and the conditions observed should suggest and schedule the next round of tests.

\section{CONCLUSIONS}

This study dealt with the design and development of maintenance protocols for the railway industry. The novelty of this approach has been highlighted as the traceability of the maintenance operations in the railway structures, which are currently mostly performed without following a systematic approach. The fundamental concept starts with the idea of having a unique systematic, traceable and repeatable approach, which would address the problems associated with 'human operator' errors. The method described the QR code as a key element, which has proved to be important to keep track of the operations and the data related to a workpiece. The approach makes it possible to actuate corrections while processing in order to decrease the amount of time spent on the secondary repeated operations that are eventually required to ensure that the designed features fulfil their capabilities. The main protocol described a systematic practical approach where a specific component is treated in several phases. Within the protocol, the existence of a retroactive system makes it possible to actively interact with the system along with the in-line monitoring process. As a consequence, time is saved from making corrections that should be done, instead, at a post-processing phase.

The case study concerning the application of the main protocol to the turning operations for the maintenance of a workpiece demonstrated the applicability of this approach in terms of input parameters and actuation systems. Through inline identification and by adjusting the most important parameters in turning, namely the depth of the cut, the spindle speed, the feed rate and the lubricant, it was possible to take an active control over the process outputs, which are the cutting force and the tool wear.

The same main protocol was adapted to the testing procedures, as in the case of the braking tests for locomotives. Each phase was systematically followed. During the testing, the pressures applied in the braking system were actively monitored and adjusted to successfully carry out the testing procedures. If the test report showed negative outputs, the control would proceed to the maintenance operations, following the required steps already set out. 
Table 1. Sample results obtained from a brake quality control made on an ordinary locomotive.

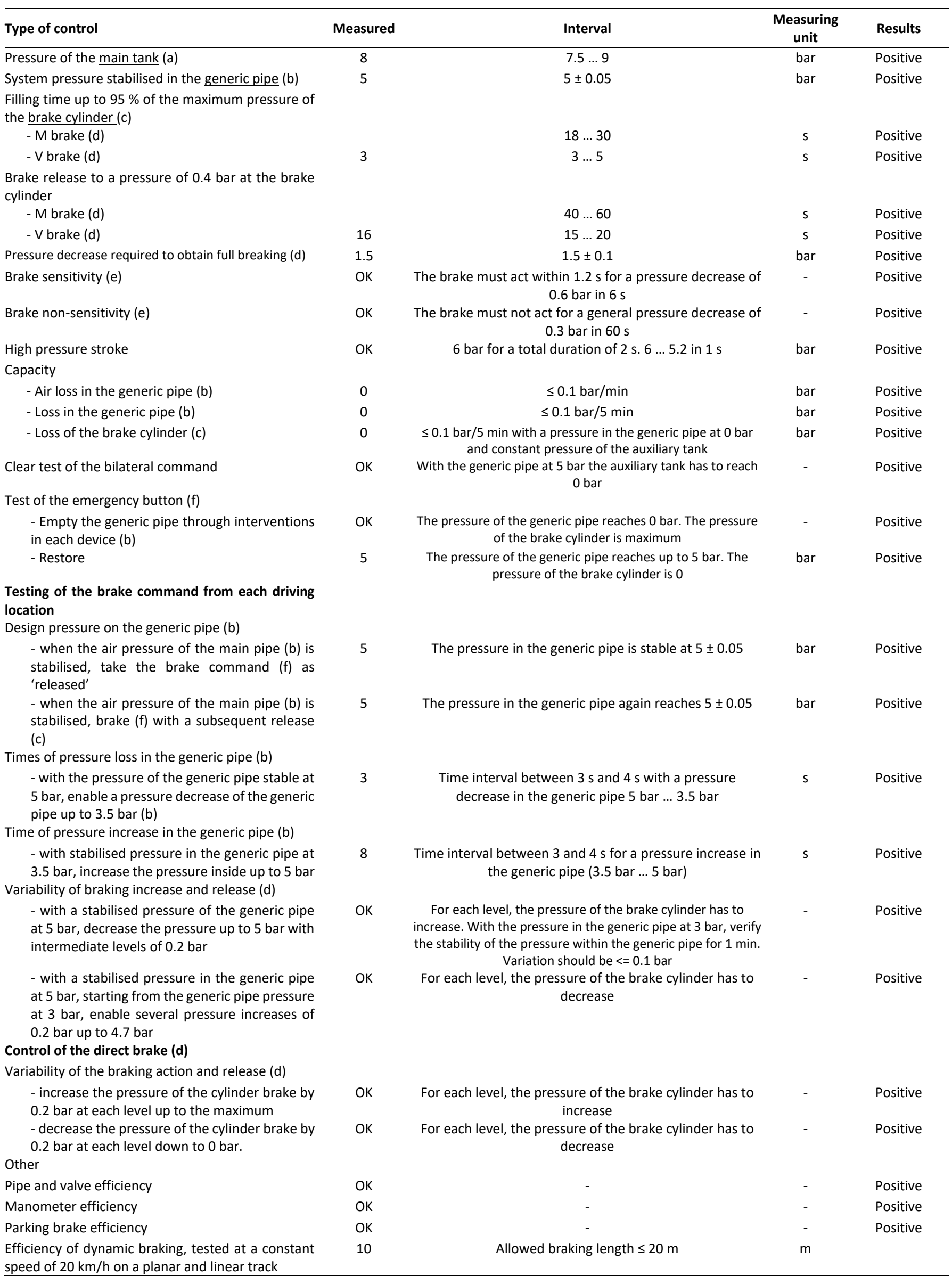


At the end of each process/test mapping, the QR code worked to keep track of these operations and maintain the traceability of the specific workpiece.

The proposed protocols can also be applied to electrical improvements and maintenance in railway applications [38], [39]. Furthermore, such protocols may be implemented in measuring systems, which are already being experimented with in the railway structure, [40] and for continuous monitoring [41].

\section{ACKNOWLEDGEMENTS}

This study has been developed in the framework of the Italian projects 'Automazione dei processi e di test di misurazione orientati alla tracciabilità della lavorazione di pezzi speciali e delle attività di officina: "TrainIndustry 4.0" (Automation of processes and measurement tests oriented towards the traceability of the processing of special parts and worker activities: 'TrainIndustry $\left.4.0^{\prime}\right)$. The authors would like to thank the Dyrecta Lab researchers, G. Birardi, B. Boussahel, A. Calicchio, D. Carella, A. Colonna, A. Costanzo, V. Custodero, A. D'Accolti, L. D'Alessandro, M. Legrottaglie, A. Leogrande, A. Lombardi, A. Lorusso, N. Malfettone, S. F. Massari, O. Rizzo, D. D. Romagno, N. Savino, S. Selicato, M. Solazzo, M. M. Sorbo, F. Tarulli and V. Vitti for their efforts. The authors would also like to thank MEDTEC srl for the support provided on the working procedures. The paper is an extended version of an earlier paper [37].

\section{REFERENCES}

[1] Frascati Manual 2015: The Measurement of Scientific, Technological and Innovation Activities - Guidelines for Collecting and Reporting Data on Research and Experimental Development. OECD (2015), ISBN 978- 926423901-2 (PDF) DOI: https://doi.org/10.1787/9789264239012-en

[2] V. Roblek, M. Meško, A. Krapež, A complex view of industry 4.0, SAGE Open April-June 2016, pp. 1-11.

[3] S. Mikawa, Industrie 4.0 and the Latest Trends in Monozukur Innovation in the Auto Industry, NEC Technical Journal 10(1) Special Issue on Enterprise Solutions to Support a Safe, Secure and Comfortable Life, December 2015, pp. 28-32.

[4] H.-C. Pfohl, B. Yahsi, T. Kurnaz, The impact of industry supply chain, Inn. Strat. Log. Supp. Chain. ISBN (online): 978-3-73754059-9, ISBN (print), pp. 978-3-73.

DOI: https://doi.org/10.13140/RG.2.1.4906.2484

[5] M. R. Khabbazi, M. D. Yusof Ismail, N. Ismail, S. A. Mousavi, Modeling of traceability information system for material flow control data, Aust. J. Bas. Appl. Sc. 4(2) (2010) pp. 208-216.

[6] L. Várallyai, From barcode to QR code applications, Agrárinformatika/Agricultural Informatics 3(2) (2012) pp. 9-17.

[7] I. T. Asare, D. Asare, The effective use of quick response (QR) code as a marketing tool, Int. J. Educ. Soc. Sc. 2(12) December 2015, pp. 67-73.

[8] T. Lotlikar, R. Kankapurkar, A. Parekar, A. Mohite, Comparative study of barcode, QR-code and RFID system, Int. J. Computer Technol. \& Appl. 4(5) 2013, pp. 817-821.

[9] A. Boob, A. Shinde, D. Rathod, A. Gaikwad, QR code based mobile app and business process Integration, Int. J. Multidisc. \& Curr. Res 2 (2014), pp. 1014-1017. Online [Accessed 01 December 2020]

http://ijmcr.com/wp-content/uploads/2014/10/Paper2310141017.pdf

[10] J. Qianyu, Exploring the concept of QR code and the benefits of using QR code for companies, Bachelor's Thesis, School of Business and Culture Degree Programme in Business Information Technology, Bachelor of Business Administration, 2014.
[11] K. H. Pandya, H. J. Galiyawala, A survey on QR codes: in context of research and application, Int. J. Emerg. Technol. Adv. Eng. 4(3), March 2014, pp. 258-262.

DOI: https://doi.org/10.14569/IJACSA.2020.0110324

[12] R. Bhandari, Impact of technology on logistics and supply chain management, IOSR J. Bus. Manag. (IOSR-JBM), e-ISSN: 2278487X, pp. 19-24. Online [Accessed 01 December 2020] http://www.iosrjournals.org/iosr-jbm/papers/7th-ibrc-volume2/17.pdf

[13] R. R. Pant, G. Prakash, J. A. Farooquie, A framework for traceability and transparency in the dairy supply chain networks, Procedia - Soc. Beh. Sc. 189 (2015) pp. 385-394. Online [Accessed 01 December 2020] https://core.ac.uk/download/pdf/82747585.pdf

[14] K. Kraisintu, T. Zhang, The role of traceability in sustainable supply chain management, Report No. E2011:085, Department of Technology Management and Economics, Division of Logistics and Transportation, Chalmers University of Technology, Göteborg, Sweden, 2011. Online [Accessed 01 December 2020] http://publications.lib.chalmers.se/records/fulltext/146242.pdf

[15] M. George, K-P. Fischer-Hellmann, M. Knahl, U. Bleimann, S. Atkinson, Traceability in model-based testing, Future Internet 4(4) (2012) pp. 1026-1036.

[16] R. Singh, I. A. Khan, An approach for integration testing in online retail applications, Int. J. Comp. Sc. \& Inf. Technoly 4(3), June 2012, pp. 141-158. DOI: https://doi.org/10.5121/ijcsit.2012.4312

[17] A. Kannenberg, H. Saiedian, Why software requirements traceability remains a challenge, 14 CrossTalk, The Journal of Defense Software Engineering, July/August 2009, pp. 14-19.

[18] Axiomtek report, Trends in Factory Automation: The Internet of Things (IoT), 2015. Online [Accessed 01 December 2020] http:/ / www.axiomtek.com.tw/ArticlePageView.aspx?ItemId=95 $\underline{\mathrm{st}=48}$

[19] I. Oditis, J. Bicevskis, The concept of automated process control, Comp. Sc. \& Inf. Technol. 756 (2010) pp. 193-203. Online [Accessed 01 December 2020] https://www.lu.lv/materiali/apgads/raksti/756 pp 193-203.pdf

[20] M. D. Okrent, R. J. Vokurka, Process mapping in successful ERP implementations, Ind. Manag. \& Dats Sys. 104(8) (2004) pp. 637643.

DOI: https://doi.org/10.1108/02635570410561618

[21] P. Frusman, D. Wibisono, Design and implementation of warehouse management improvement strategy using barcode systems approach at pt latinusa tbk, ICTOM $04-$ The $4^{\text {th }}$ International Conference on Technology and Operations Management, Kuala Lumpur, Malaysia, 18 - 20 August 2014, pp. 230-238. Online [Accessed 01 December 2020] http://www.stmlportal.net/ictom04/papers/P23.pdf

[22] A. Chakraborty, Importance of PDCA cycle for SMEs, SSRG Int. J. of Mech. Eng. 3(5) (2016), pp. 13-17. DOI: https://doi.org/10.14445/23488360/IJME-V3I5P105

[23] R. H. Fouad, A. Mukattash, Statistical process control tools: a practical guide for Jordanian industrial organizations, Jordan Journal of Mechanical and Industrial Engineering 4(6), December 2010, pp. 693-700. Online [Accessed 01 December 2020] http://jimie.hu.edu.jo/files/v4n6/4.pdf

[24] P. Li, P. Jiang, G. Zhang, An enhanced DMAIC method for the feature-driven continuous quality improvement for multi-stage machining processes in one-of-a-kind and small-batch production, IEEE Access 7 (2019) pp. 32492-32503. DOI: https://doi.org/10.1109/ACCESS.2019.2900461

[25] J. Krauß, M. Frye, G. T. D. Beck and R. H. Schmitt, Selection and application of machine learning algorithms in production quality, Technologien für die intelligente Automation 9 (2019) pp. 46-57. DOI: https://doi.org/10.1007/978-3-662-58485-9 6

[26] D. F. Hesser, B. Markert, Tool wear monitoring of a retrofitted CNC milling machine using artificial neural networks, Manufact. Lett. 19(1) (2019) pp. 1-4. DOI: https://doi.org/10.1016/j.mfglet.2018.11.001 
[27] P. Cozzucoli, Process Monitoring with Multivariate $p$-Control Chart. International Journal of Quality, Statistics, and Reliability, August 2009. DOI: https://doi.org/10.1155/2009/707583

[28] P. Li, P. Jiang, G. Zhang, An Enhanced DMAIC Method for Feature-Driven Continuous Quality Improvement for Multi-Stage Machining Processes in One-of-a-Kind and Small-Batch Production, IEEE Access. 7, 2019, pp. 32492-32503. DOI: https://doi.org/10.1109/ACCESS.2019.2900461

[29] C. Escobar, R. Morales-Menendez, Machine learning techniques for quality control in high conformance manufacturing environment, Advances in Mechanical Engineering, 10(2):168781401875551, February 2018. DOI: https://doi.org/10.1177/1687814018755519

[30] E. Sezer, D. Romero, F. Guedea, M. Macchi, C. Emmanouilidis, Christos, An Industry 4.0-Enabled Low Cost Predictive Maintenance Approach for SMEs, IEEE International Conference on Engineering, Technology and Innovation (ICE/ITMC), Stuttgart, Germany, 17-20 June 2018. DOI: https://doi.org/10.1109/ICE.2018.8436307

[31] P. Neto, J. N. Pires, A. Moreira, Accelerometer-Based Control of an Industrial Robotic Arm, Proc. of the IEEE International Workshop on Robot and Human Interactive Communication, Toyama, Japan, 27 September - 2 October 2009, pp. 1192 - 1197. DOI: https://doi.org/10.1109/ROMAN.2009.5326285

[32] E. Cannella, C. V. Nielsen, N. Bay, Process investigation and mechanical properties of electro sinter forged (ESF) titanium discs, International Journal of Advanced Manufacturing Technology 104(i), October 2019, pp. 1985-1998. DOI: https://doi.org/10.1007/s00170-019-03972-z

[33] E. Cannella, C. V. Nielsen, N. Bay, On the process and product fingerprints for electro sinter forging (ESF), Micromachines 10(4) (2019). DOI: https://doi.org/10.3390/mi10040218

[34] R. Davis, V. Singh, S. Priyanka, Optimization of process parameters of turning operation of EN 24 steel using Taguchi design of experiment method, Proceedings of the World Congress on Engineering, Vol. II, London, UK, 2-4 July 2014. Online
[Accessed 01 December 2020] http://www.iaeng.org/publication/WCE2014/WCE2014 pp10 45-1047.pdf

[35] G. Arefi, R. Das, A. Sahoo, B. Routara, B. Nanda, A study on the effect of machining parameters in turning of lead alloy, Materials Today: Proceedings 4(8) 2017, pp. 7562-7572.

DOI: https://doi.org/10.1016/i.matpr.2017.07.088

[36] D. V. V. Krishan Prasad, Influence of cutting parameters on turning process using Anova analysis, Research Journal of Engineering Sciences 2(9) (2013) pp. 1-6.

[37] A. Massaro, N. Contuzzi, A. Galiano, I. Manfredonia, B. Xhahysa, A Preliminar Research industry project: a case of study defining requirements for knowledge base gain and technological upgrade in industry working in train parts processing and testing, IEEE International Workshop on Metrology for Industry 4.0 and IoT, IEEE Proceeding, Naples, Italy, 4-6 June 2019, pp. 172-176.

DOI: https://doi.org/10.1109/METROI4.2019.8792850

[38] A. Mariscotti, Characterization of power quality transient phenomena of DC railway traction supply, Acta IMEKO 1(1) (2012) pp. 26-35.

DOI: https://doi.org/10.21014/acta imeko.v1i1.17

[39] J. Bongiorno, A. Mariscotti. Accuracy of railway track conductance and joint efficiency measurement methods, Acta IMEKO 4(4) (2015) pp. 82-87.

DOI: https://doi.org/10.21014/acta imeko.v4i4.270

[40] J. Yang, Q. Feng, A new method for measuring subgrade settlement in high-speed railway by using a linear CCD, Measurement 46(5) (2013) pp. 1751-1756. DOI: https://doi.org/10.1016/i.measurement.2012.11.049

[41] P. Salvador, V. Naranjo, R. Insa, P. Teixeira, Axlebox accelerations: Their acquisition and time-frequency characterisation for railway track monitoring purposes, Measurement 82 (2016) pp. 301-312.

DOI: https://doi.org/10.1016/i.measurement.2016.01.012 